\title{
Chapter 9 \\ Extractability and Chemical Forms of Radioactive Cesium in Designated Wastes Investigated in an On-Site Test
}

\author{
Yoko Fujikawa, Hiroaki Ozaki, Xiaming Chen, Shogo Taniguchi, \\ Ryouhei Takanami, Aiichiro Fujinaga, Shinji Sakurai, and Paul Lewtas
}

\begin{abstract}
In the aftermath of the 2011 accident at Fukushima Daiichi Nuclear Power Plant (F1 hereafter), municipal solid waste (MSW) contaminated with radioactive cesium (rad-Cs hereafter) has been generated in 12 prefectures in Japan. The Japanese Minister of Environment classified MSW that contained rad-Cs in the concentration more than $8,000 \mathrm{~Bq} / \mathrm{kg}$ as "designated (solid) waste (DSW hereafter), and prescribed the collection, storage and transportation procedures. When MSW containing rad-Cs was incinerated, rad-Cs was concentrated in fly ash, and the ash often fell into the category of DSW. We have investigated a technique that can reduce the volume of the rad-Cs-contaminated fly-ash by extracting rad-Cs with aqueous solvents such as water and oxalic acid and concentrating rad-Cs in a small amount of hexacyanoferrate (or ferrocyanide, designated as Fer hereafter) precipitate. Since DSW could not be transported to the outside laboratory, we have conducted on-site tests at places where DSW were generated to investigate the applicability of the extraction - precipitation technique.

The present report is a summary of our most recent on-site test conducted in 2014. Also presented is the re-evaluation of the results of our past on-site test from the viewpoint of leaching of rad-Cs and heavy metals in the fly ash. An apparent decrease in leaching of rad-Cs from fly ash was observed by incinerating sewage sludge with soil. Fly ash from a melting furnace contained more water-soluble radCs than that from a fluidized-bed incinerator. Some incinerator fly ash appeared to
\end{abstract}

\footnotetext{
Y. Fujikawa ( $\square)$

Kyoto University Research Reactor Institute, Asahiro-nishi, Kumatori-cho, Sennan-gun, Osaka 590-0458, Japan

e-mail: fujikawa@rri.kyoto-u.ac.jp

H. Ozaki • X. Chen • S. Taniguchi • R. Takanami • A. Fujinaga

Osaka Sangyo University, 3-1-1 Nakagaito, Daito city, Osaka 574-8530, Japan

S. Sakurai

Osaka Prefecture University, 1-1 Gakuen-cho, Naka-ku, Sakai-shi, Osaka 599-8531, Japan

P. Lewtas

Edith Cowan University, 270 Joondalup Drive, Joondalup, WA 6027, Australia
} 
produce rad-Cs in colloidal form when extracted with oxalic acid, resulting in the lower removal of rad-Cs from the extract by Fer method.

Keywords Ferrocyanide (hexacyanoferrate) • Radioactive cesium • Designated waste $\bullet$ Leaching $\bullet$ Water $\bullet$ Oxalic acid

\subsection{Background Information on the Aftermath of the F1 Accident}

Four years have passed since the 2011 Eastern Japan Great Earthquake Disaster and the F1 accident that resulted in the first case of widespread contamination of the general environment with rad-Cs in Japan. Millions of people have continued to live in the zone that received rad-Cs fallout higher than the level of background global fallout observed in the middle latitudes of the northern hemisphere [1, 2]. Public and semi-public services indispensable for daily life, e.g. supply of electricity and potable water, sewage treatment, garbage collection, public transportation, etc., had been reconstructed relatively quickly after the 2011 disaster (e.g. [3, 4]). Among these services in the affected areas, potable and sewage water treatment and garbage collection have produced drinking water treatment sludge, sewage sludge, and incinerator ashes containing elevated concentration of rad-Cs. Both disposal and reuse have become difficult for such wastes, resulting in sludge and ashes piling up in many treatment facilities.

The government of Japan has proposed to construct landfills with special leachate collection and treatment systems along with a radiation monitoring system for the disposal of wastes with rad-Cs concentration higher than $8,000 \mathrm{~Bq} / \mathrm{kg}$ (so-called DSW). But so far the plan has stalled due to public criticism. We have summarized the situation in our previous reports $[5,6]$, and the situation has remained unchanged concerning the final disposal of DSW.

\subsection{Strategy of Volume Reduction and Stabilization of Municipal Solid Waste and Designated Waste in Japan}

Under the circumstances delineated above, the volume reduction of various wastes contaminated with rad-Cs is of paramount importance. The thermal treatment, with emphasis on incineration, has been the topmost strategy for stabilization and volume reduction of municipal and industrial wastes in Japan [7]. Also, thermal treatment has been a recommended option for volume reduction of combustible radioactive wastes for a long time [8]. Consequently, incineration has been planned and conducted on vegetation and paddy straw removed in the course of the cleanup work and sewage sludge contaminated with rad-Cs from the area with high rad-Cs 
fallout, resulting in generation of bottom ash and fly ash possessing diverse leaching characteristics of rad-Cs and non-radioactive hazardous components.

In Japan, various pretreatment procedures have been studied and administered for incinerated MSW before burying the waste in landfills [9, 10]. The purpose of the pretreatment had been to accelerate the waste stabilization, namely to prevent the leaching of toxic elements, hazardous organic substances and dissolved and/or suspended organic matters related with BOD and COD values, from the waste. Among such procedures was the washing of ashes with acid or water (e.g. [11, 12]). The washing effectively removed the major elements from MSW incineration ashes and also reduced the leachability of toxic elements from the washed residues. In a full-scale acid extraction process, washed ash became a stabilized cake to be buried in a landfill, solid salt was recycled to soda production plants, condensed water was recycled in the plant as cooling water and no wastewater was discharged from the plant [11]. More recently, a group of researchers and engineers proposed the "wash out waste" (WOW) system in which solid waste was inactivated by washing before landfilling, resulting in rapid stabilization of the buried waste and early closure of the landfill [13]. The WOW system can reduce the possibility of long-term contamination of the environment by landfill leachate, and may also help gain public support for the siting of landfills.

After the F1 accident and the concomitant pollution of MSW with rad-Cs, wastewashing technology has drawn the attention of researchers and private companies again. The nature of $\mathrm{Cs}$ in incinerated (or in some case smelted) ashes and the decontamination technology to remove rad-Cs from the wastes or waste extracts have been investigated [5, 6, 14-16]. Parajuli et al. [14] pointed out that the percentage of water-soluble rad-Cs is much smaller in sewage ash compared to that in wood and garbage ash, probably because of clay minerals of pedogenic origin present in the sewage sludge. Saffarzadeh et al. [15] studied the behaviour of Cs in bottom ash using stable Cs salts in a pilot incinerator, and reported that Cs in bottom ash could be most commonly found in the silicate glass matrix. Kozai et al. [16] studied the mineralogical components of sewage sludge ashes and reported that the majority of rad-Cs was in the $\mathrm{HCl}$-soluble phase, and was probably contained in iron oxides.

The fly ash washing technique to eliminate rad-Cs has been also studied by some private companies, and the initial and running cost of the technology has been estimated [17]. In the processes developed by the companies, the use of Fer compounds to remove rad-Cs from the washing solution was a prerequisite. A report by the Institute of National Environmental Studies [18] defined the category of rad-Cs containing wastes for which washing processes can be applied and the performance requirements as well as radiation safety standard of the washing system. 


\subsection{Principle of Ferrocyanide Coprecipitation for Cs Removal}

The principle of the Fer method for removal of Cs is reviewed in literatures [19-21], as well as in our previous report [5,6]. In brief, the method utilizes the extremely high affinity of the Cs cation to insoluble Fer compounds. The insoluble Fer compounds are prepared by reacting soluble Fer salts (K, Na or $\mathrm{H}$ compounds) with metal ( $\mathrm{Fe}, \mathrm{Cu}, \mathrm{Zn}, \mathrm{Ni}, \mathrm{Cd}, \mathrm{Mn}$, etc.) ions in solution.

There are three different ways to use Fer in order to remove Cs: (1) addition of soluble Fer salts and metal elements to waste solution (in situ formation of Fer solid), (2) addition of freshly prepared insoluble Fer metal complex slurry to waste solution and (3) use of Fer-metal adsorbents in solution. The distribution ratio of Cs to insoluble Fer compounds is high in the order of method (1)>(2)>(3). Throughout our experiment, we have used method (1) (in situ method) as much as possible, and have used method (2) (addition of the fresh Fer solid) when method (1) could not be used, e.g. when $\mathrm{Zn}$ concentration in the solution is very high and $\mathrm{Zn}$-Fer was going to be the prevalent Fer solid to be formed.

\subsection{The Waste Volume Reduction When Ferrocyanide Coprecipitation Technique Was Used}

We have been working on a technique that extracts rad-Cs from DSW (especially rad-Cs contaminated fly ash) with water or hot oxalic acid, and selectively removes rad-Cs from the extract as a small amount of precipitate utilizing the Fer coprecipitation technique. The focus of our research has been to achieve the efficient removal of rad-Cs from the waste extracts having a complex composition. So far, we have found that more than $95 \%$ of rad-Cs could be removed from the extracts of MSW under an optimized combination of $\mathrm{pH}$, Fer concentration and type of metalFer complex formed in the extract. A high $\mathrm{Zn}$ concentration in the extract suppressed the removal of Cs by the Fer precipitation method [5, 6].

The waste volume reduction $d[\%]$ and the ratio of rad-Cs concentration in the precipitate to that of the original waste $Q_{\mathrm{Cs}} / C_{0}$ are estimated by the following equation:

$$
\begin{aligned}
& d=100\left(1-\frac{p V}{M}\right) \\
& \frac{Q_{\mathrm{Cs}}}{C_{0}}=\frac{100}{100-d} r E
\end{aligned}
$$


where $M$ : weight $[\mathrm{kg}]$ of MSW extracted by $V[\mathrm{~L}]$ of the solvent, $p[\mathrm{~kg} / \mathrm{L}]$ : weight of Fer precipitate formed per unit volume of the extract, $Q_{\mathrm{Cs}}[\mathrm{Bq} / \mathrm{kg}]$ : rad-Cs concentration $[\mathrm{Bq} / \mathrm{kg}]$ in Fer precipitate, $C_{0}[\mathrm{~Bq} / \mathrm{kg}]$ : rad-Cs concentration in original MSW, $r$ : ratio of rad-Cs removed from the extract of MSW by Fer technique, and $E$ : ratio of rad-Cs extracted from MSW with solvent.

We estimated the volume reduction $d(\%)$ experimentally by a cold run using fly ash of sewage sludge obtained from the area unaffected by rad-Cs from the F1 accident [22]. The procedures are as follows: $M[\mathrm{~kg}]$ of fly ash samples was extracted with $V[\mathrm{~L}]$ of oxalic acid or distilled water, $100 \mu \mathrm{g} / \mathrm{L}$ of Cs133 (stable isotope of $\mathrm{Cs}$ ) as $\mathrm{CsCl}$ salt was added to the extract as a spike, and Fer coprecipitation was conducted to remove Cs from the extract. After the coprecipitation, the precipitate was separated from the liquid by centrifugation $\left(6,400 \mathrm{~g}, 4^{\circ} \mathrm{C}, 15 \mathrm{~min}\right)$, freeze dried and weighed to estimate the value of $p[\mathrm{~kg} / \mathrm{L}]$. The Cs concentration in the supernatant after Fer coprecipitation was determined by ICP-MS to estimate the Cs removal ( $r$ in Eq. 9.2). The $d(\%)$ values for actual DSW used in our on-site test were not obtained due to the shortage of time during the test.

The results obtained are summarized in Table 9.1. When concentration of Fer added for the removal of Cs was $0.1 \mathrm{mM}$, the theoretical $d(\%)$ value is $99.3 \%$ for oxalic acid extract and $99.99 \%$ for water extract, under the assumptions that the solid-to-liquid ratio of the extraction of waste was $1 \mathrm{~g} / 2.5 \mathrm{~mL}$, that the extract was diluted by a factor of 100 when the extracting reagent was $1 \mathrm{M}$ oxalic acid (factor of 2 when the reagent was water) before subjecting it to Fer coprecipitation and that the Fer solid is anhydrous. As shown in the table, the observed $d(\%)$ values were generally higher than $99.9 \%$ for the water extract and were close to the theoretical value. On the other hand, $d(\%)$ values were low for oxalic acid extract especially when Fer coprecipitation was conducted at circumneutral or alkaline $\mathrm{pH}$. The original oxalic acid extract had low $\mathrm{pH}$ (c.a. 1), and as we added $\mathrm{NaOH}$ to increase the $\mathrm{pH}$ of the solution, the precipitates of metal hydroxides were formed. It was also noted that the oxalic acid extract of fly ash KO had a lower volume reduction compared to that of fly ash $\mathrm{O}$ under the same $\mathrm{pH}$ values. This is ascribed to the high amount of Fe contained in the extract of fly ash $\mathrm{KO}$ [6], starting to precipitate around $\mathrm{pH} 3$. In summary, for the oxalic acid extract, higher waste volume reduction is achieved by conducting the Fer coprecipitation at $\mathrm{pH}$ value as low as possible so that the formation of metal hydroxide precipitate can be suppressed.

Overall, the results in Table 9.1 indicate that Fer coprecipitation leads to significant reduction in the amount of the waste (more than $1 / 1,000$ for waste extracted with water, or nearly $1 / 100$ for waste extracted with oxalic acid), under appropriate operating conditions. The waste residue after the extraction contains a low concentration of rad-Cs, and, since the extractable rad-Cs was removed from the residue, the long-term contamination of the environment caused by leaching of rad-Cs from the buried waste residue is expected to be negligible. Combined with proper management (e.g. storage) of the small volume of rad-Cs concentrated waste, the siting of the final disposal site of DSW is expected to become much easier. 
Table 9.1 Volume reduction of the waste by extraction-precipitation method (results of cold run)

\begin{tabular}{|c|c|c|c|c|c|c|c|c|}
\hline \multirow[b]{2}{*}{$\begin{array}{l}\text { Extracting } \\
\text { reagent }\end{array}$} & \multirow[b]{2}{*}{$\begin{array}{l}\text { Fer } \\
{[\mathrm{mM}]^{\mathrm{a}}}\end{array}$} & \multirow{2}{*}{$\begin{array}{l}\mathrm{pH} \\
\mathrm{pH}\end{array}$} & \multicolumn{3}{|c|}{ Fly ash O } & \multicolumn{3}{|c|}{ Fly ash $\mathrm{KO}$} \\
\hline & & & $d \%^{\mathrm{b}}$ & $r$ & $\left(Q_{\mathrm{Cs}} / \mathrm{C}_{0}\right) / E$ & $d \%^{\mathrm{b}}$ & $r$ & $\left(Q_{\mathrm{Cs}} / \mathrm{C}_{0}\right) / E$ \\
\hline \multirow{9}{*}{$\begin{array}{l}\text { Distilled } \\
\text { water } 1 \mathrm{~g} / 2.5 \mathrm{~mL} \\
\text { solid to liquid } \\
\text { ratio }\end{array}$} & \multirow[t]{7}{*}{0.1} & 3 & n.a. & 0.959 & n.a. & $99.9<$ & 0.952 & $667<$ \\
\hline & & 4 & 99.933 & 0.946 & 1,401 & 99.916 & 0.990 & 827 \\
\hline & & 5 & $99.9<$ & 0.958 & $671<$ & 99.935 & 0.959 & 1,031 \\
\hline & & 6 & $99.9<$ & 0.933 & $653<$ & 99.985 & 0.995 & 4,642 \\
\hline & & 7 & 99.961 & n.a. & n.a. & 99.963 & 0.992 & 1,851 \\
\hline & & 8 & 99.848 & 0.988 & 454 & 99.965 & 1.000 & 1,999 \\
\hline & & 10 & 99.911 & 0.985 & 63 & 99.713 & 0.993 & 242 \\
\hline & 0.5 & 5 & $99.9<$ & 0.974 & $682<$ & 99.970 & 0.989 & 2,305 \\
\hline & 1.0 & 5 & $99.9<$ & 0.942 & $659<$ & 99.961 & 0.999 & 1,793 \\
\hline \multirow{9}{*}{$\begin{array}{l}1 \mathrm{M} \text { oxalic } \\
\text { acid }^{\mathrm{d}} 1 \mathrm{~g} / 2.5 \mathrm{~mL} \\
\text { solid to liquid } \\
\text { ratio }\end{array}$} & \multirow[t]{7}{*}{0.1} & 3 & 98.66 & 0.999 & 74 & 82.33 & 0.998 & 6 \\
\hline & & 4 & 94.41 & 0.996 & 18 & 77.45 & 0.998 & 4 \\
\hline & & 5 & 90.32 & 0.969 & 10 & 74.04 & 0.957 & 4 \\
\hline & & 6 & 86.58 & 0.978 & 7 & 78.65 & 0.937 & 4 \\
\hline & & 7 & 83.69 & 0.960 & 6 & 70.65 & 0.963 & 3 \\
\hline & & 8 & 77.82 & 0.926 & 4 & 63.43 & 0.962 & 3 \\
\hline & & 10 & 76.79 & 0.924 & 4 & 76.11 & 0.919 & 4 \\
\hline & 0.5 & 5 & 97.68 & 0.998 & 43 & 69.35 & 0.985 & 3 \\
\hline & 1.0 & 5 & 88.07 & 0.988 & 8 & 69.74 & 0.928 & 3 \\
\hline
\end{tabular}

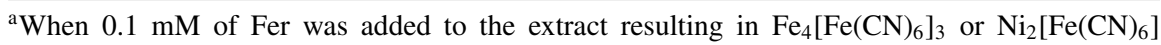
precipitate, the weight of the precipitate is 29 or $34 \mathrm{mg} / \mathrm{L}$ respectively (excluding the weight of the hydrated water)

${ }^{\mathrm{b}}$ Theoretically, volume reduction $d(\%)$ is $99.3 \%$ for oxalic acid extract and $99.99 \%$ for distilled water extract based on the weight of the anhydrous Fer solid

${ }^{\mathrm{c}}$ The extract was diluted by a factor of 2 before subjecting it to the Fer coprecipitation

${ }^{\mathrm{d}}$ The extract was diluted by a factor of 100 before subjecting it to the Fer coprecipitation

\subsection{Objectives of the Present Study}

The extraction-coprecipitation method described above can be an ultimate solution for volume reduction of DSW. The waste volume reduction $d(\%)$ in Eq. 9.1 is an important factor in assessing the effectiveness of the method, but also important is the relative concentration of the rad-Cs in the precipitate compared to that in the original waste. Higher values of $Q_{\mathrm{Cs}} / C_{0}$ imply that rad-Cs is concentrated more efficiently in the precipitate compared to the waste residues after the extraction, thereby defining the overall effectiveness of the method.

The starting point of our study has been to identify the factors that are likely to govern the rad-Cs removal (i.e. $r$ in Eq. 9.2) from DSW extracts by Fer coprecipitation technique, and to optimize coprecipitation conditions for Cs removal. Based on this perspective, we evaluate the results of our most recent (fiscal year 2014) on-site test using DSW in the present report. 
Leachability of rad-Cs in the DSW (i.e. $E$ in Eq. 9.2) is another important factor that governs the effectiveness of the extraction-coprecipitation method. We therefore evaluated the results of our 2013 and 2014 on-site tests to examine the leaching of rad-Cs from sewage sludge ashes. Also important are the leaching characteristics of heavy metals. High leaching of $\mathrm{Fe}$ and $\mathrm{Ni}$ from waste is convenient in our study since these metals can be effectively used for the formation of insoluble Fer precipitate. On the other hand, high leaching of $\mathrm{Zn}$ is inconvenient because $\mathrm{Zn}$ forms insoluble Fer precipitate when soluble Fer salt is added to the solution, but the removal efficiency of Cs by Zn-Fer is low [6]. In this context, in the present report, we also examine the leaching of heavy metals from the fly ash samples.

\subsection{Experimental}

\subsubsection{Reagents}

All reagents used in our study were of analytical grade unless specified otherwise.

\subsubsection{Procedures of Cold Run}

We used MSW fly ash samples unaffected by the F1 accident to clarify the effect of extracting procedures on the extraction efficiency of various elements (including non-radioactive cesium) from the sample. In particular, we compared the use of 0.1 and $0.5 \mathrm{M}$ hot oxalic acid extraction procedures on fly ash from a melting furnace treating sewage sludge from Western Japan. Since the sample was not contaminated with rad-Cs from the F1 accident, the extraction could be conducted in the university laboratory, and the concentration of various elements in the extracts could be determined using ICP-MS (model 7700 series, Agilent Technologies).

The three different extraction procedures were tested on the fly ash sample from the melting furnace. (1) One procedure was vacuum extraction (or continuous extraction), in which a $5 \mathrm{~g}$ fly ash sample placed on an i.d. $47 \mathrm{~mm}$ membrane filter holder (fitted with pore size $0.45 \mu \mathrm{m}$ PTFE filter) was continuously eluted with hot oxalic acid $(50 \mathrm{~mL}$ solution/40 min) supplied via a peristaltic pump for total $120 \mathrm{~min}$. The filter holder was connected to a vacuum flask, and vacuum was applied periodically so that the extracting reagent ( 0.1 or $0.5 \mathrm{M}$ hot oxalic acid) was passed through the filter while the fly ash sample was always soaked in the oxalic acid. The percolate was collected every $40 \mathrm{~min}$, and was analyzed by ICP-MS. By using the vacuum extraction method, re-adsorption of once extracted components to the waste material, as well as temporary oversaturation of extracted metals in the solution phase, could be minimized. This procedure was also practicable in the on-site test. (2) Conventional batch extraction ( $2.5 \mathrm{~g}$ of fly ash in $75 \mathrm{~mL}$ of 0.1 or $0.5 \mathrm{M}$ hot 
oxalic acid), with $200 \mathrm{rpm}$ of shaking in a $90{ }^{\circ} \mathrm{C}$ hot bath, was conducted. (3) Also tested was a batch exchange extraction method, an intermediate method between continuous extraction and batch extraction. With this method, $2.5 \mathrm{~g}$ of fly ash was extracted with $25 \mathrm{~mL}$ of $0.1 \mathrm{M}$ or $0.5 \mathrm{M}$ hot oxalic acid with continuous shaking (200 rpm) in a hot bath for $1 \mathrm{~h}$, centrifuged for solid-liquid separation $(6,400 \times \mathrm{g}$, $4{ }^{\circ} \mathrm{C}, 15 \mathrm{~min}$ ), and the supernatant was removed and saved for the subsequent analysis by ICP-MS. Then $25 \mathrm{~mL}$ of 0.1 or $0.5 \mathrm{M}$ hot oxalic acid was added to the solid waste again and the same extraction procedure repeated twice. The batch exchange method turned out to be laborious and was not practicable in the on-site test compared to the other two methods.

With hot oxalic acid extraction, a precipitate was sometimes formed in the extract after it was cooled to room temperature. In such cases, the extract was centrifuged, the precipitate was dissolved in dilute $\mathrm{HNO}_{3}$ and the supernatant and the dissolved precipitate were analyzed separately by ICP-MS.

To determine the total element concentration in the fly ash, $100 \mathrm{mg}$ of the fly ash sample, pulverized to pass a 150 mesh sieve, was digested by mineral acids in a pressurized Teflon vessel placed in a microwave oven model MARS5000 (CEM Co., US). The acids used were $5 \mathrm{~mL}$ of concentrated $68 \% \mathrm{HNO}_{3}, 1 \mathrm{~mL}$ of $70 \%$ $\mathrm{HClO}_{4}$ and $4 \mathrm{~mL}$ of $38 \% \mathrm{HF}$. All the acids used were AA-100 grade from Tama Chemicals Corporation (Japan). The sample was acid decomposed under 70 psi pressure for $10 \mathrm{~min}$. after $20 \mathrm{~min}$. of ramp time. After the decomposition, $6 \mathrm{~mL}$ of $4.1 \mathrm{w} / \mathrm{v}$ percent boric acid was added to the digested sample to dissolve the fluoride precipitated with $\mathrm{Ca}$, etc. as well as to neutralize HF left in the solution. With this procedure, a clear solution with no visible suspended particles was obtained. The solution was diluted and analyzed by ICP-MS. The results obtained were used to calculate the percentages of the elements extracted by 0.1 or $0.5 \mathrm{M}$ oxalic acid from the fly ash per total amount of the elements in the original fly ash.

\subsubsection{Determination of Radioactive Cs and Non-radioactive Metals in the On-Site Test}

On-site analysis of rad-Cs was conducted using a portable Ge detector from Princeton Gamma Technology (P-type, relative efficiency $20 \%$ ), and a Ge detector from ORTEC (model Trans-Spec, p-type, relative efficiency $40 \%$ ), in 2013 and 2014 , respectively. Ge detectors were pre-calibrated for absolute full-energy peak efficiency for the solid samples packed in commercially available U-8 vessels (i.d. $50 \mathrm{~mm}$, height $68 \mathrm{~mm}$ ) as well as for a $30 \mathrm{~mL}$ volume of aqueous solution in a $50 \mathrm{~mL}$ polypropylene bottle, and were used to quantitate rad-Cs in waste extracts and waste materials. A NaI detector (model AN-OSP-NAI, Hitachi-Aloka-Medical, pre-calibrated for determination of rad-Cs) was also used to quantitate Cs-134 and Cs-137 in waste materials. 
Concentrations of metals in the extract obtained at the on-site test were determined using a portable voltammetry instrument (model PDV6000plus from Modern Water, UK) coupled with an autosampler. In 2014, Fe and Zn were determined. Determination of $\mathrm{Fe}$ was conducted using a glassy carbon working electrode, acetate buffer as a supporting electrolyte, deposition potential $-1,600 \mathrm{mV}$ and stripping step potential range of $-1,100$ to $50 \mathrm{mV}$. Determination of $\mathrm{Zn}$ was conducted at a mercury-film-coated glassy carbon working electrode, acetate buffer as a supporting electrolyte, deposition potential $-1,300 \mathrm{mV}$ and stripping step potential range of $-1,200$ to $50 \mathrm{mV}$.

\subsubsection{Extraction Procedures Used in the On-Site Test}

The rad-Cs-contaminated fly ash samples from sewage treatment in the area affected by the F1 accident were extracted and analyzed for rad-Cs in the plant where they were produced (the on-site test). The information for the waste materials used for the on-site test is summarized in Table 9.2, together with extracting reagents tested on the samples. We used a distilled-water extraction [23] and a hot oxalic acid $(0.1 \mathrm{M})$ extraction [24] that had previously been applied to the removal of radCs from contaminated MSW. Also tested were $5 \mathrm{M} \mathrm{HCl}$ extraction and $0.5 \mathrm{M}$ hot oxalic acid extraction in an attempt to achieve higher leaching of rad-Cs for some samples.

The extraction of rad-Cs containing waste materials was conducted using the vacuum extraction (continuous extraction) procedure in the on-site test conducted in 2014. This procedure was used because the results of three different extraction methods for uncontaminated waste showed that the batch extraction may be affected by loss of the extracted elements due to re-adsorption and/or precipitation processes as will be discussed in the Sect. 9.7. The extraction in 2013 was conducted by batch extraction.

\subsubsection{Ferrocyanide Coprecipitation Procedures Used at the On-Site Test}

The treatment of the extract by Fer precipitation technique was conducted as follows: The $\mathrm{pH}$ of the waste extract containing rad-Cs was adjusted to the desired values (shown later in Sect. 9.7) using $\mathrm{NaOH}$ and $\mathrm{HCl}$. Potassium ferrocyanide $\left(\mathrm{K}_{4}\left[\mathrm{Fe}(\mathrm{CN})_{6}\right]\right.$, K-Fer hereafter) was used as a soluble Fer salt source. Since metal hydroxides (ineffective for $\mathrm{Cs}$ removal) rather than metal-Fer complexes could be formed in the solutions when $\mathrm{pH}$ values are in neutral to alkaline regions, a slightly acidic $\mathrm{pH}$ was used for Fer precipitation. After the addition of K-Fer, Ni-Fer or $\mathrm{Fe}(\mathrm{III})-\mathrm{Fer}$ precipitate (prepared in a separate bottle) to the extract, the sample was 


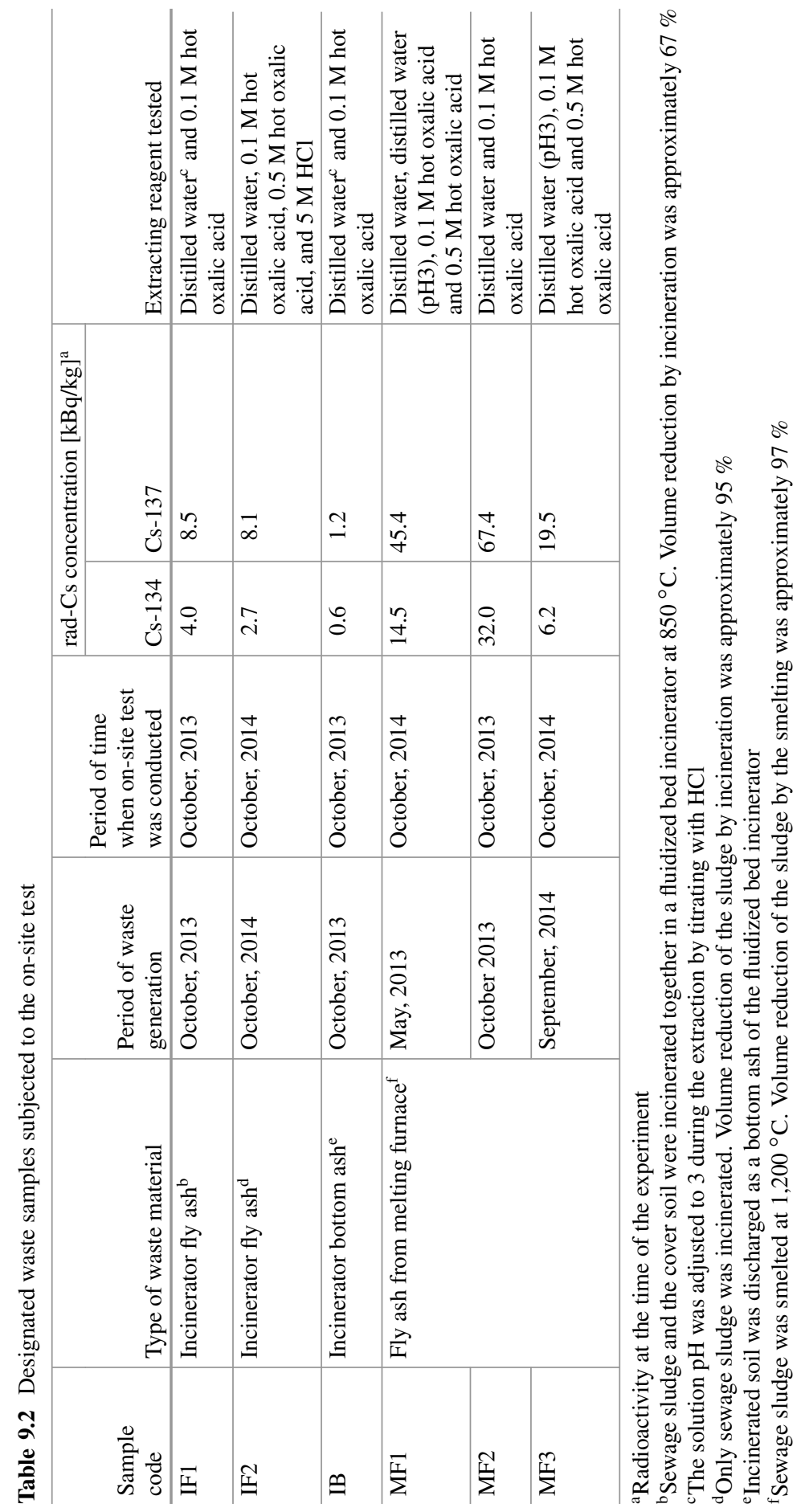


centrifuged at $2,600 \times \mathrm{g}$ at $4{ }^{\circ} \mathrm{C}$ for $20 \mathrm{~min}$. or stood still until the precipitate was settled. When more than a few liters of the extract were treated, $30 \mathrm{mg} / \mathrm{L}$ of cationic polymeric flocculant (polymethacrylic ester, C-303 or C-512 from MT AquaPolymer Inc., Japan) was added to facilitate the settling of fine precipitates.

\subsection{Results and Discussion}

\subsubsection{Extraction of Metal Elements from Fly Ash Sample in the Cold Run}

Extractions of stable (non-radioactive) $\mathrm{Ca}, \mathrm{Fe}, \mathrm{Zn}, \mathrm{Ni}$, As and $\mathrm{Cs}$ from fly ash (collected from a melting furnace treating sewage sludge from Western Japan) with 0.1 and $0.5 \mathrm{M}$ hot oxalic acid are compared in Fig. 9.1. Clearly, the percentages of metal extraction differed considerably depending on the concentration of oxalic acid as well as on the extraction procedures (continuous, batch and batch exchange). With the batch extraction procedure, we observed a high extraction percentage at an earlier time (40 min), followed by a decrease in the extraction percentage. This is probably explained by re-adsorption or re-precipitation (or co-precipitation) of once extracted elements. In contrast, the continuous extraction showed a gradual increase in extraction percentages with time. The extraction percentages by continuous extraction at 120 min of extraction time were similar to those obtained by batch extraction at $40 \mathrm{~min}$ for non-radioactive $\mathrm{Cs}$ and $\mathrm{Fe}$. The batch exchange procedure method showed a gradual increase in the extraction percentages of the elements with time and was more similar to the continuous extraction than simple batch extraction. For both batch and batch exchange procedures, there could have been temporary oversaturation of the extracted elements in the solution after 40 min of extraction with hot oxalic acid. In the case of the batch exchange method, the oversaturated elements, if any, should have been precipitated during the centrifugation to exchange the supernatant. In simple batch extraction, unlike batch exchange extraction, supernatant was not exchanged, and the aliquot of the supernatant collected for analysis should contain the oversaturated element (if any). In any case, the batch exchange procedure was laborious compared to the continuous extraction and simple batch methods. Also, the centrifugation we conducted for solid-liquid separation in the batch exchange procedure every 40 min caused a temporary decrease in the extraction temperature, making it difficult to interpret the obtained results.

The oxalic acid concentration of the extract also affected the extraction efficiency of elements (in Fig. 9.1, only the results of $\mathrm{Ca}, \mathrm{Fe}, \mathrm{Zn}, \mathrm{Ni}$, As and $\mathrm{Cs}$ are shown). Briefly, in the case of continuous extraction, $0.5 \mathrm{M}$ hot oxalic acid was more effective than $0.1 \mathrm{M}$ hot oxalic acid in extracting non-radioactive $\mathrm{Cs}, \mathrm{Fe}, \mathrm{Mg}, \mathrm{Al}$, $\mathrm{Mn}, \mathrm{As}, \mathrm{Se}, \mathrm{Sr}$ and $\mathrm{Ba}$. On the other hand, for $\mathrm{Zn}, \mathrm{Ca}, \mathrm{Co}, \mathrm{Ni}$ and $\mathrm{Cu}, 0.1 \mathrm{M}$ hot oxalic acid was more effective than $0.5 \mathrm{M}$ hot oxalic acid (in the case of continuous 

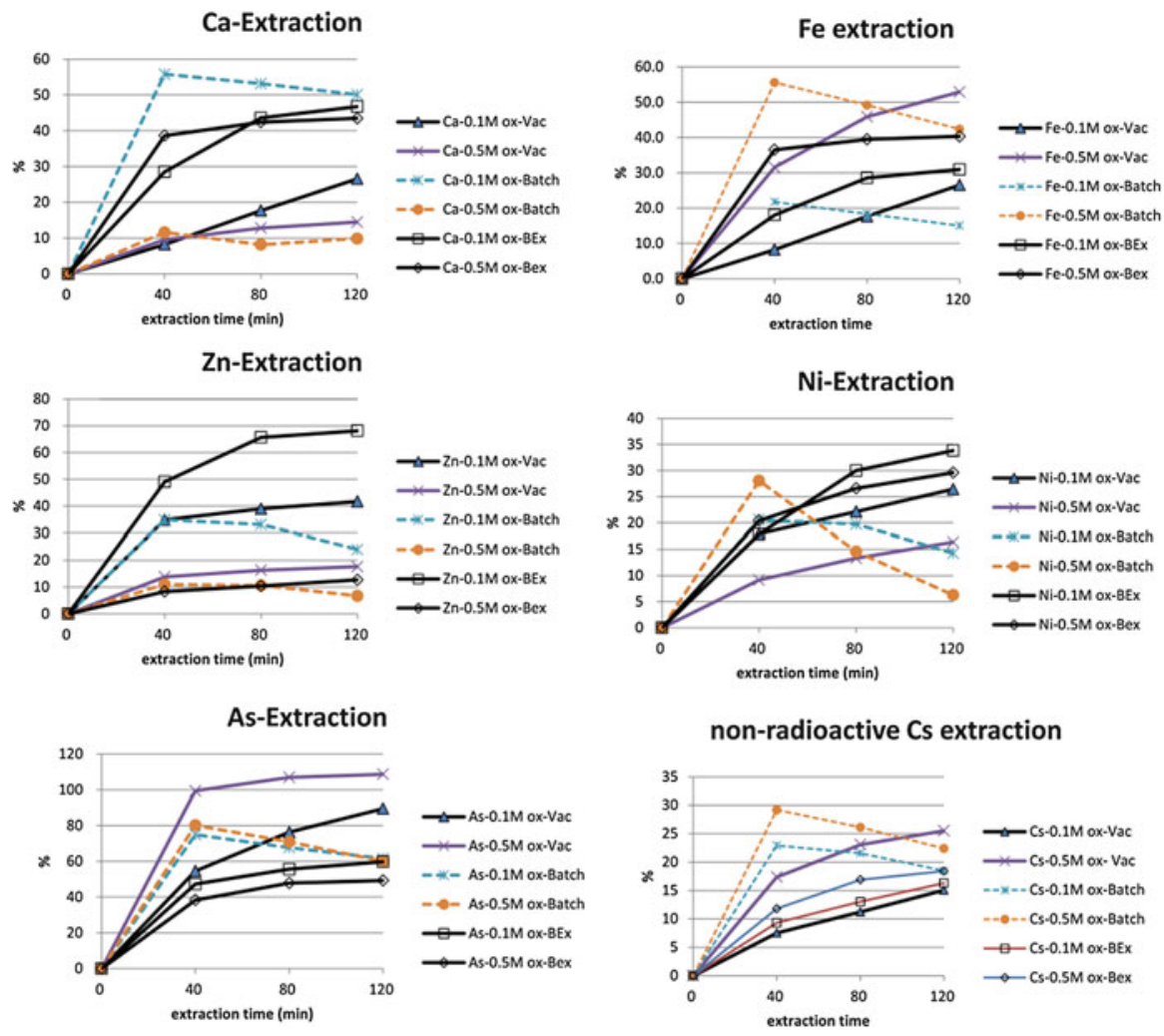

Fig. 9.1 Comparison of extraction rate of various elements with continuous (vacuum extraction), batch extraction, and batch exchange extraction methods for fly ash from a melting furnace. Here, $0.1 \mathrm{M}$ ox $-V$ ac: continuous extraction with $0.1 \mathrm{M}$ hot oxalic acid, $0.5 \mathrm{M}$ ox $-V$ ac: continuous extraction with $0.5 \mathrm{M}$ hot oxalic acid, $0.1 \mathrm{M}$ ox-Batch: batch extraction with $0.1 \mathrm{M}$ hot oxalic acid, $0.5 \mathrm{M}$ ox-Batch: batch extraction with $0.5 \mathrm{M}$ hot oxalic acid, $0.1 \mathrm{M}$ ox - Bex: batch exchange extraction with $0.1 \mathrm{M}$ hot oxalic acid, and $0.5 \mathrm{M}$ ox - Bex: batch exchange extraction with $0.5 \mathrm{M}$ hot oxalic acid

extraction). Oxalic acid dissolves Fe and some other metals preferentially through the ligand-promoted dissolution process [25], and the lower $\mathrm{pH}$ of $0.5 \mathrm{M}$ oxalic acid compared to $0.1 \mathrm{M}$ oxalic acid enhances the dissolution of elements in general. At the same time, with $0.5 \mathrm{M}$ oxalic acid, metal oxalates having low solubility can be more easily formed than with $0.1 \mathrm{M}$ oxalic acid. We consider that the concentrations of $\mathrm{Zn}, \mathrm{Ca}, \mathrm{Co}, \mathrm{Ni}$ and $\mathrm{Cu}$ in the $0.5 \mathrm{M}$ oxalic acid extract were solubility controlled by the metal oxalates. Although the solubility values of metal oxalates freshly formed at high temperature $\left(90^{\circ} \mathrm{C}\right)$ may be hard to obtain, solubility determined for pure metal oxalates can be used as reference values. According to the literature [26], oxalates of $\mathrm{Zn}, \mathrm{Co}, \mathrm{Ni}$ and $\mathrm{Cu}$ have very low solubility at $20^{\circ} \mathrm{C}$. This information supports our inference that $\mathrm{Zn}, \mathrm{Co}, \mathrm{Ni}$ and $\mathrm{Cu}$ concentrations were solubility controlled. Since the concentration of $\mathrm{Ca}$ in the extract is high (between 67 
and $600 \mathrm{mg} / \mathrm{L}$ in $0.5 \mathrm{M}$ oxalic acid extract), it is no wonder that the Ca concentration was controlled by the solubility of calcium oxalate.

Based on the results above, we applied the continuous extraction method at the on-site test in 2014, in order to obtain more scientific estimates of the leaching of rad-Cs from the contaminated fly ash. We noted, however, that the behavior of non-radioactive Cs during the extraction was relatively simple, i.e. Cs was not precipitated with oxalic acid and therefore its extraction was higher in $0.5 \mathrm{M}$ oxalic acid than in $0.1 \mathrm{M}$ oxalic acid, and the highest extraction could be achieved with $40 \mathrm{~min}$ of batch extraction. From a practical point of view, by using $0.5 \mathrm{M}$ hot oxalic acid in simple batch extraction mode, the majority of Cs that can be extracted with the reagent by the continuous method will be released from the solid phase, although there is a chance that the behavior of non-radioactive Cs we have investigated in this section and that of rad-Cs in fly ash samples are different, depending on the original chemical form of Cs.

\subsubsection{Extraction of rad-Cs from Contaminated Fly Ash Samples}

The results are summarized in Table 9.3. The results indicate rad-Cs leaching from melting furnace fly ash (MF1, MF2 and MF3) is high. At least $40 \%$ was extracted with distilled water, and the percentage of the rad-Cs extraction was close to $100 \%$ when $0.5 \mathrm{M}$ hot oxalic acid was used. Notably, the percentages of rad-Cs extraction were not much affected by the $\mathrm{pH}$ values of the extract. For example, distilled water extracts of MF3 had $\mathrm{pH}$ values around 7 (refer to Table 9.3), and rad-Cs extraction was higher than $60 \%$. The distilled water extracts of MF2 had lower $\mathrm{pH}$ values (around 1) compared to $\mathrm{MF3}$, and the rad-Cs extraction was only $40 \%$, lower than the distilled water extracts of $\mathrm{MF} 3$ with $\mathrm{pH}$ value 7 . The lower extraction percentages for MF2 are partly attributable to the lower solid-to-liquid ratio $(1 \mathrm{~g} / 2.5 \mathrm{~mL})$ of extraction compared to $1 \mathrm{~g} / 75 \mathrm{~mL}$ for MF3, implying that a thorough washing with larger volume of liquid leads to higher leaching.

As discussed in the preceding section, stable Cs extracted by distilled water from fly ash of the melting furnace treating sewage sludge from Western Japan was only $5 \%$ of the total Cs contained in the ash. Interestingly, rad-Cs in the fly ash MF1, MF2 and MF3 from the similar melting furnace was more water soluble compared to the stable cesium in the other fly ash of similar origin.

The extractability of rad-Cs was lower for incinerator fly ash (IF1 and IF2) compared to fly ash from the melting furnace (MF1, MF2 and MF3). The ashes collected in different periods, IF1 and IF2, also exhibited quite different leaching of rad-Cs, Fe and $\mathrm{Zn}$. When extracted with distilled water, rad-Cs extraction percentages were only ca. $1 \%$ for IF1, whereas it was $10 \%$ or higher for IF2. The IF2 ash also had higher amount of extractable Fe and Zn compared to IF1. The IF1 ash was obtained when sewage sludge was incinerated together with soil, while IF2 


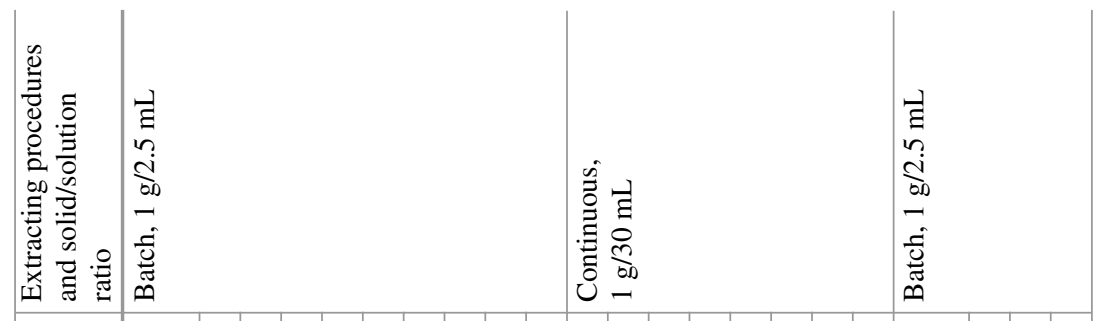

$\triangle$

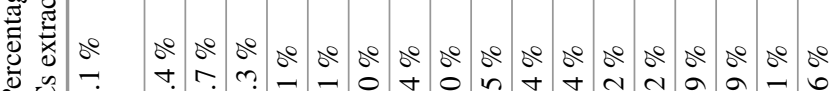

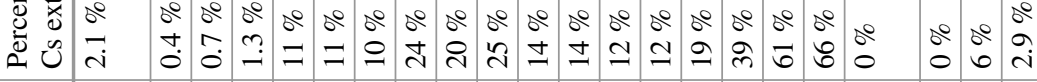

$\widehat{\frac{\sigma}{\sigma}}$

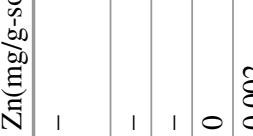

ڤిరి

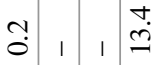

$\stackrel{0}{0}$

స్ㅎำ

I

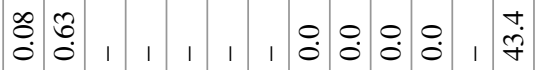

రా.

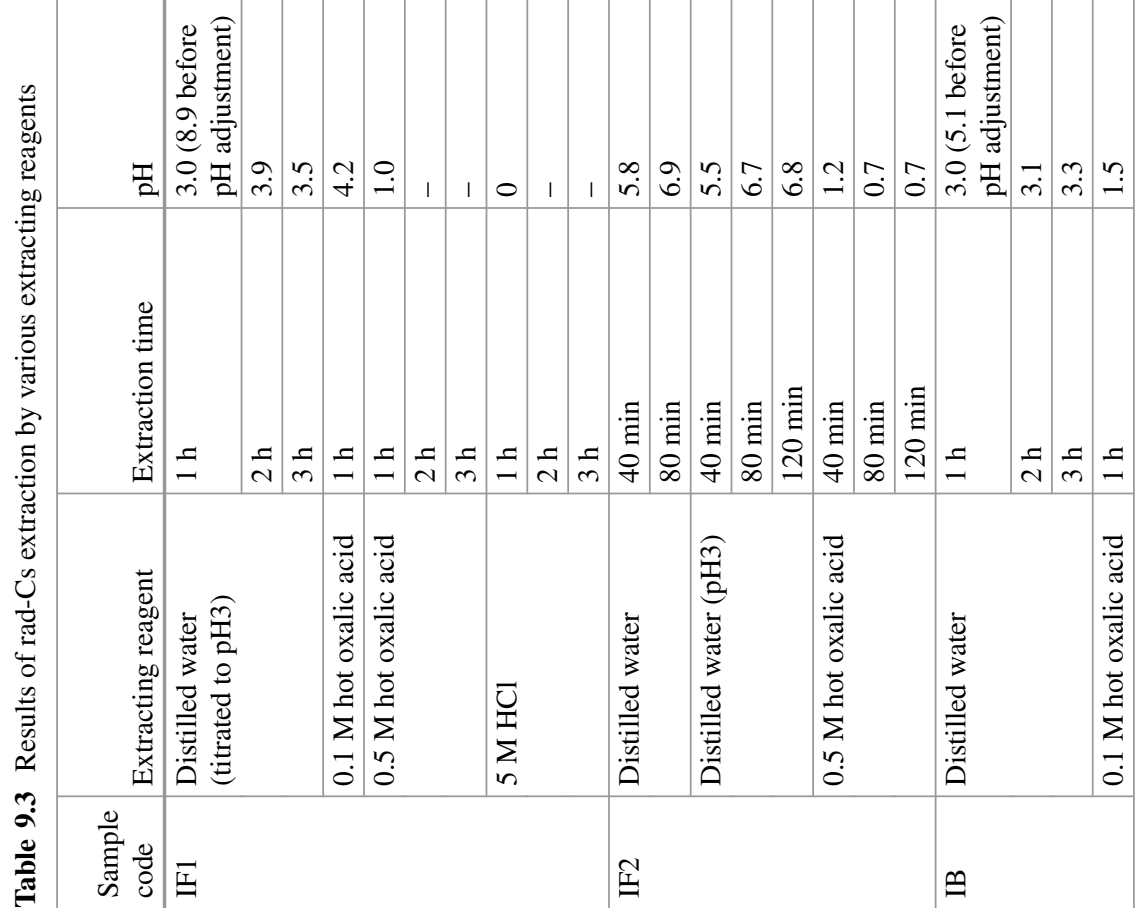


9 Extractability and Chemical Forms of Radioactive Cesium in Designated...

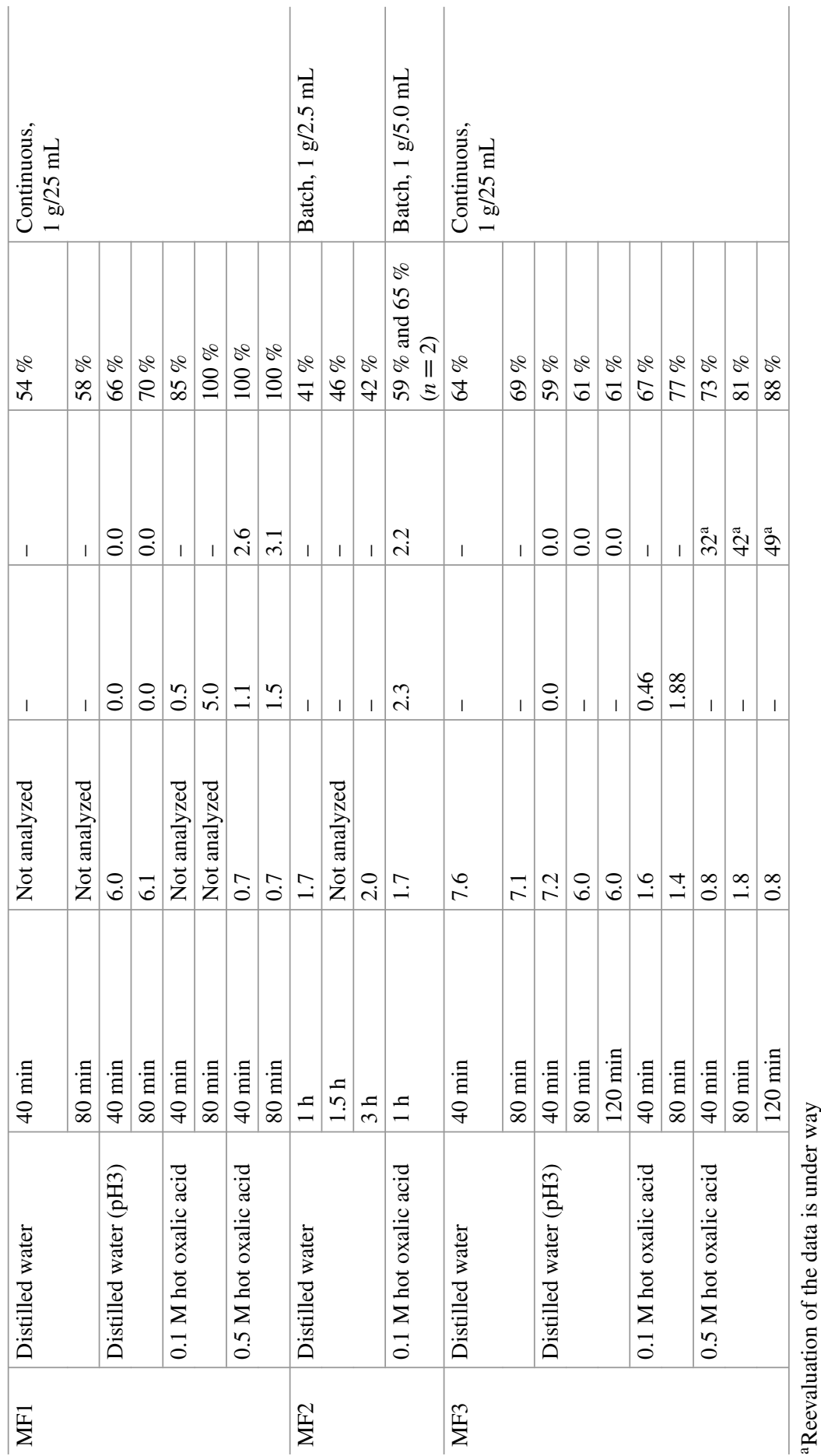


ash was obtained when only sewage sludge was incinerated. The other researchers [9] pointed out that the incineration with soil is likely to inhibit the leaching of rad-Cs from the fly ash, and the results we obtained are in accordance with their observation. As for IF1, we also used $5 \mathrm{M} \mathrm{HCl}$ extraction in an effort to facilitate the leaching of rad-Cs, but the percentage of rad-Cs extracted was only $20 \%$ with this method. Kozai et al. [11] reported that leaching of rad-Cs from sewage ash can be enhanced by pulverizing the ash and using hot $\mathrm{HCl}$ extraction. Out of concern for safety, we could not conduct the pulverizing of already fine-grained, powderlike incinerator fly ash nor use hot $\mathrm{HCl}$ during our on-site test. In contrast, more than $60 \%$ of rad-Cs in IF2 was extracted with $0.5 \mathrm{M}$ hot oxalic acid (the percentage was $10 \%$ for IF1). We cannot rule out the possibility that the continuous extracting procedure we used for IF2 (IF1 was extracted by batch method) was more effective in leaching rad-Cs from the sample. However, as we discussed in the section above, the leaching behavior of $\mathrm{Cs}$ is relatively simple because of the high solubility of $\mathrm{Cs}$ in water, and it is unlikely that the difference in extraction procedure (continuous or batch) led to a drastic difference in the extraction rate with the same hot oxalic acid. We therefore conclude that the incinerating of sewage sludge and soil together in the fluidized bed incinerator led to the drastic reduction of rad-Cs leaching from fly ash.

The bottom ash IB1, which in fact is the soil incinerated in the fluidized bed incinerator, exhibited a very low leaching of rad-Cs $(0 \%$ with distilled water and $3 \%$ with $0.1 \mathrm{M}$ hot oxalic acid). Considering the reduction in leaching of rad-Cs from fly ash, it is obvious that rad-Cs leaching was inhibited in the presence of soil. It should be noted that the soil itself did not contain much rad-Cs before it was incinerated. The rad-Cs contained in the bottom ash originated from contaminated sewage sludge.

\subsubsection{Ferrocyanide Coprecipitation in On-Site Test}

Table 9.4 shows results of Fer coprecipitation conducted on extracts of rad-Cs contaminated fly ash. The extract of molten fly ash showed c.a. $93 \%$ removal of radCs when $\mathrm{Fe}$ (III)-ferrocyanide or Ni(II) -ferrocyanide was added and the supernatant was analyzed. Removal of rad-Cs, when we tried the in situ formation of insoluble Fer solids by adding Fe(III) salt and K-Fer salt, was only $80 \%$ because the very fine precipitate formed could not be completely removed, even though we added a coagulant. Optimal solid-liquid separation for the in situ Fer solid formation method needs to be pursued further.

As for the extracts of incinerator ash IF2, only one oxalic acid extract sample contained an easily detectable amount of $\mathrm{rad}-\mathrm{Cs}(235 \mathrm{~Bq} / \mathrm{L})$. We therefore focused on the removal of rad-Cs from this sample. After some trial and error, we conducted coprecipitation with $\mathrm{Ni}(\mathrm{II})$-ferrocyanide at $\mathrm{pH}$. The resultant removal of rad-Cs was only $59 \%$. 
Table 9.4 Removal of rad-Cs from the solution under different $\mathrm{pH}$ and ferrocyanide concentrations (FY 2014 on-site test results)

\begin{tabular}{l|l|l|l|l|l}
\hline Sample type & $\begin{array}{l}\text { Cs-137 Bq/L } \\
\text { in raw water }\end{array}$ & $\mathrm{pH}$ & $\begin{array}{l}\text { Ferrocyanide } \\
\text { concentration }\end{array}$ & Metal added & Removal \% \\
\hline $\begin{array}{l}0.3 \mathrm{M} \text { oxalic acid } \\
\text { extract of fly ash } \\
\text { from a smelting } \\
\text { furnace }\end{array}$ & 800 & 2 & $\begin{array}{l}0.6 \mathrm{mM} \text { iron } \\
\text { ferrocyanide }\end{array}$ & $\begin{array}{l}\text { (Fe(III)- } \\
\text { ferocyanide) }\end{array}$ & $93.8 \%^{\mathrm{a}}$ \\
\hline $\begin{array}{l}\text { Water extract of fly } \\
\text { ash from a smelting } \\
\text { furnace }\end{array}$ & 842 & $\begin{array}{l}\text { Between } \\
\text { fund } 4\end{array}$ & $\begin{array}{l}0.1 \mathrm{mM} \\
\text { potassium } \\
\text { ferrocyanide }\end{array}$ & $\begin{array}{l}0.4 \mathrm{mM} \\
\text { Fe(III) }\end{array}$ & $80.9 \%$ \\
\hline $\begin{array}{l}\text { Water extract of fly } \\
\text { ash from a smelting } \\
\text { furnace }\end{array}$ & 842 & 7 & $\begin{array}{l}0.1 \mathrm{mM} \\
\text { nickel } \\
\text { ferrocyanide }\end{array}$ & $\begin{array}{l}\text { (Ni(II)- } \\
\text { ferrocyanide) }\end{array}$ & $92.50 \%$ \\
\hline $\begin{array}{l}\text { 0.5 M oxalic acid } \\
\text { extract of fly ash } \\
\text { from an incinerator }\end{array}$ & 33 & $\begin{array}{l}\text { Between } \\
\text { ferrocyanide }\end{array}$ & $\begin{array}{l}\text { (Fe(III)- } \\
\text { ferocyanide) }\end{array}$ & $100 \%$ \\
$\begin{array}{l}\text { foncentrated } 0.5 \mathrm{M} \\
\text { oxalic acid extract of } \\
\text { fly ash from an } \\
\text { incinerator }\end{array}$ & 235 & 7 & $\begin{array}{l}\text { Cs-137 n.d. } \\
\text { nickel } \\
\text { ferrocyanide }\end{array}$ & $\begin{array}{l}\text { (Ni(II)- } \\
\text { ferrocyanide) }\end{array}$ & $58.8 \%$ treated \\
\hline $\begin{array}{l}\text { Water extract of fly } \\
\text { ash from an } \\
\text { incinerator }\end{array}$ & 15 & 3.9 & $\begin{array}{l}0.1 \mathrm{mM} \text { iron } \\
\text { ferrocyanide }\end{array}$ & $\begin{array}{l}\text { (Fe(III)- } \\
\text { ferocyanide) }\end{array}$ & $100 \%$ \\
\hline
\end{tabular}

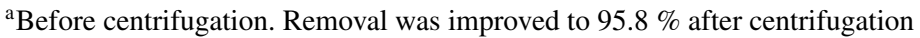

${ }^{\mathrm{b}}$ The result of ultrafiltration suggested that about $34 \%$ of radioactive cesium was in the particulate form

To investigate the cause of this low removal of rad-Cs, in the 2014 on-site test, the $0.5 \mathrm{M}$ oxalic acid extracts of fly ashes from the incinerator and melting furnace (both pre-filtered by a pore size $0.45 \mu \mathrm{m}$ membrane filter) were ultra-filtered using molecular weight (MW) 3,000 Sartorius centrifugal ultrafiltration kit. The extract of fly ash from the melting furnace left no residue on the ultrafilter, indicating that there are probably no colloidal particles in the extract of the melting furnace. On the other hand, the extract of the incinerator ash was retained on the ultra-filter, and by analyzing the rad-Cs content of the retained liquid, c.a. $30 \%$ of rad-Cs in the extract was estimated to be colloidal ( $\mathrm{MW}>3,000$ ).

These results explain why rad-Cs removal from the $0.5 \mathrm{M}$ oxalic acid extract of the incinerator fly ash by Fer coprecipitation was low (58\%). Only rad-Cs cations can be removed by the Fer precipitation technique, and if the rad-Cs in colloidal form in the incinerator fly ash extract had been in cationic form, the removal of rad-Cs would have increased to c.a. $90 \%$, i.e. the removal that should be attained with the Fer method under normal circumstances. As for the extract of incinerator fly ash, we also observed the low removal of rad-Cs in the on-site test in 2013 and attributed the results to the lack of time to optimize the coprecipitation conditions 
for the sample [6]. However, based on the recent findings, the low removal of rad-Cs in the 2013 test was also likely to have been the effect of rad-Cs being present in colloidal form. Although the conversion of the colloidal rad-Cs to rad-Cs cations may not be easy, by selecting and using an appropriate coagulant, colloidal rad-Cs can be removed by coagulation and precipitation. The origin of the colloidal rad-Cs in the extract needs to be investigated in the future research.

\subsection{Conclusion}

Extraction of fly ashes generated from sewage treatment plants in the area affected by the F1 accident was investigated, followed by the selective removal of Cs using Fer precipitation techniques. The extraction of Rad-Cs was lower for incinerator fly ash compared to fly ash from the melting furnace. When sewage sludge was incinerated with soil, leaching of rad-Cs from the fly ash was significantly reduced. It was also noted that the leaching of rad-Cs from fly ash of the melting furnace was probably higher than that of stable Cs. Colloidal (non-ionic) rad-Cs, found in incinerator fly ash extract, reduced the Cs removal by Fer precipitation technique. The use of an appropriate coagulant that can coagulate the colloidal rad-Cs should greatly improve the Cs removal.

Open Access This chapter is distributed under the terms of the Creative Commons Attribution Noncommercial License, which permits any noncommercial use, distribution, and reproduction in any medium, provided the original author(s) and source are credited.

\section{References}

1. United Nations Scientific Committee on the Effects of Atomic Radiation (2000) Report to the general assembly, with scientific annexes Annex C Exposures to the public from man-made sources of radiation. http://www.unscear.org/docs/reports/annexc.pdf. Accessed 30 Mar 2015

2. Ministry of Education, Culture, Sports, Science and Technology (2011) Map of soil contamination with radioactive cesium. http://www.mext.go.jp/b_menu/shingi/chousa/gijyutu/017/ shiryo/_icsFiles/afieldfile/2011/09/02/1310688_2.pdf. Accessed 11 Apr 2014

3. Ministry of Land, Infrastructure, Transport and Tourism (2012) Water resources in Japan as of fiscal year 2012. http://www.mlit.go.jp/tochimizushigen/mizsei/hakusyo/H24/2-9.pdf. Accessed 11 Apr 2014

4. Fujikawa Y (2011) Action of the engineers and scientists from Osaka and Kyoto in response to the accident in the Fukushima Daiichi nuclear power plant. Jpn J Health Phys 46(3):244-245

5. Fujikawa Y, Wei P, Fujinaga A, Tsuno H, Ozaki H, Kimura S (2013) Removal of cesium from the extract of municipal water treatment sludges by precipitation with ferrocyanide solids. In: Proceedings of the 15th international conference on environmental remediation and radioactive waste management, Belgium, 8-12 Sept 2013, ICEM2013-96320

6. Fujikawa Y, Ozaki H, Tsuno H, Wei P, Fujinaga A, Takanami R, Taniguchi S, Kimura S, Giri RR, Lewtas P (2014) Volume reduction of municipal solid wastescontaminated with 
radioactive cesium by ferrocyanide coprecipitation technique. In: Nakajima K (ed) Nuclear back-end and transmutation technology for waste disposal: beyond the Fukushima accident. Springer, pp 329-341

7. Ministry of the Environment (2012) Solid waste management and recycling technology of Japan - toward a sustainable society. http://www.env.go.jp/recycle/circul/venous_industry/en/ brochure.pdf. Accessed 30 Mar 2015

8. International Atomic Energy Agency (2003) Application of thermal technologies for processing radioactive waste. IAEA Tecdoc 1527. International Atomic Energy Agency, Vienna

9. Sakai S (1996) Municipal solid waste management in Japan. Waste Manag 16(4):95-405

10. Nabeshima Y (1996) Summary of research on waste minimization studies by Japan Waste Research Foundation (JWRF). Waste Manag 16(4):407-415

11. Katsuura H, Inoue T, Hiraoka M, Sakai S (1996) Full-scale plant study on fly ash treatment by the acid extraction process. Waste Manag 16(4):491-499

12. Kim SY, Matsuto T, Tanaka N (2003) Evaluation of pre-treatment methods for landfill disposal of residues from municipal solid waste incineration. Waste Manag Res 21:416-423

13. Furuta H, Matsumoto S, Higuchi S, Misumi F, Hashimoto T, Nakamura H, Horii Y (2006) Feasibility studies for practical use of the WOW system. APLAS, Shanghai, pp 252-260

14. Parajuli D, Tanaka H, Hakuta Y, Minami K, Fukuda S, Umeoka K, Kamimura R, Hayashi Y, Ouchi M, Kawamoto T (2013) Dealing with the aftermath of Fukushima Daiichi nuclear accident: decontamination of radioactive cesium enriched ash. Environ Sci Technol 47:3800 38706

15. Saffaradeh A, Shimaoka T, Kakuta Y, Kawano T (2014) Cesium distribution and phases in proxy experiments on the incineration od radioactively contaminated waste from Fukushima area. J Environ Radioact 136:76-84

16. Kozai N, Suzuki S, Aoyagi N, Sakamoto F, Ohnuki T (2015) Radioactive fallout cesium in sewage sludge ash produced after the Fukushima Daiichi nuclear accident. Water Res 68:616626

17. Technical Advisory Council on Remediation and Waste Management (2013) Technical information of the treatment and final disposal of incinerated ash. http://tacrwm.jp/03_techinfo/ pdf/03_03/03_03_01_report_pub.pdf, (in Japanese)

18. National Institute for Environmental Studies (2014) Technical information on washing of fly ash. http://www.nies.go.jp/shinsai/flyashwash_2014.6.pdf, (in Japanese)

19. Haas PA (1993) A review of information on ferrocyanide solids for removal of cesium from solutions. Sep Sci Technol 28(17\&18):2479-2506

20. Loos-Neskovic C, Fedoroff M (1989) Fixation mechanisms of cesium on nickel and zinc ferrocyanides. Solvent Extr Ion Exch 7(1):131-158

21. Barton GB, Hepworth JL, McClannaham ED Jr, Moore RL, Van Tuyl HH (1958) Chemical processing wastes: recovering fission products. Ind Eng Chem 50(2):212-216

22. Fujikawa Y, Wei P, Tsuno H, Ozaki H, Fujinaga A, Tanitguchi S, Takanami R, Sakurai S (2014) Waste volume reduction ratio when ferrocyanide coprecipitation technique was applied for decontamination of solid waste contaminated with radioactive cesium. In: 69th meeting of Japan Society of Civil Engineers, 10-12 Sept 2014, Osaka, (in Japanese)

23. Nishizaki Y, Miyamae H, Takano T, Izumiya K, Kumagai N (2012) Removal of radioactive cesium from molten fly ash. J Environ Conserv Eng 41(9):569-574

24. Ministry of Land, Infrastructure, Transport and Tourism (2011) Measures against radioactivity in the sewage system, outline of the study and the outcome. http://www.mlit.go.jp/common/ 000213235.pdf. Accessed 15 Jun 2013

25. Stumm W, Morgan JJ (1981) Aquatic chemistry, Chap. 13. Wiley Interscience, New York

26. Patnaik P (2004) Dean's analytical chemistry handbook, Chap. 4, 2nd edn. McGraw-Hill, New York 